\title{
Pediatric burns: A decade later
}

\author{
George KB Sándor MD DDS FRCDC FRCSC FACS, Howard M Clarke MD PhD FAAP FACS, \\ Hugh G Thomson MD MS FRCSC FACS, Ronald M Zuker MD FRCSC FACS \\ Division of Plastic Surgery, The Hospital for Sick Children and Department of Surgery, \\ University of Toronto, Toronto, Ontario
}

\begin{abstract}
GKB Sándor, HM Clarke, HG Thomson, RM Zuker. Pediatric burns: A decade later. Can J Plast Surg 1997;5(4):210-212. The Hospital for Sick Children, Toronto, Ontario serves as a regional pediatric burn centre for metropolitan Toronto and the province of Ontario. The demographics and outcomes of the admissions of burn patients are reviewed periodically to help in future planning of resources and preventive strategies. This study was designed to review recent admissions and detect trends of the past decade by comparing admission and outcome data from two cohorts: one from 1986 to 1988 and one from 1977 to 1979. The number of admissions increased during the past decade. There was a lower proportion of patients with flame burns and a higher proportion with scald burns. This may be due to a combination of preventive measures and changing demographics. The overall mortality rate decreased from $2.2 \%$ in the previous decade to $0.78 \%$ in the past decade.
\end{abstract}

Key Words: Flame burns, Pediatric burns, Scalds

\section{Les brûlures chez l'enfant : une décennie plus tard}

RÉSUMÉ : Le Toronto Hospital for Sick Children, en Ontario, est le centre des grands brûlés pédiatriques de la région pour le Toronto métropolitain et la province de l'Ontario. Les caractéristiques démographiques et les résultats obtenus chez des patients brûlés admis à l'unité sont revus périodiquement afin que l'on puisse planifier l'utilisation des ressources et les stratégies de prévention. Cette étude a été conçue pour passer en revue les admissions récentes et pour déceler les tendances qui se dégagent de la dernière décennie en comparant les données sur les admissions et les résultats des traitements de deux cohortes : l'une, de 1986 à 1988, et l'autre, de 1977 à 1979. Le nombre d'admissions a augmenté au cours de la dernière décennie. On note une proportion moindre de patients ayant été brûlés par des flammes et une proportion plus grande de patients ayant été ébouillantés. Cela peut être attribuable à une combinaison de mesures de prévention et à des changements des caractéristiques démographiques. Le taux de mortalité global est passé de 2,2\% pour la décennie précédente à $0,78 \%$ pour la dernière.

A s a major pediatric burn centre for the province of Ontario, The Hospital for Sick Children, Toronto, Ontario reviews its experience with burns regularly. Comparison with the previous decade is helpful for future planning within the burn unit. An even more significant role is in planning future efforts in prevention and community education based on recent trends from clinical observation.

\section{PATIENTS AND METHODS}

The records of 255 burn patients admitted to The Hospital for Sick Children, Toronto, Ontario from 1986 to 1988 were reviewed with respect to the following parameters: age, sex, etiology, anatomical area involved, extent of burn, days of hospitalization and need for intravenous resuscitation, escharotomy and grafting. Contributing factors, associated inju-

Correspondence and reprints: Dr George KB Sándor,

The Hospital for Sick Children, 555 University Avenue, Toronto, Ontario M5G 1X8. Telephone 416-813-6008, fax 416-813-6375,

e-mail gsandor@sickkids.on.ca ries, home remedies, complications and mortality were noted. These parameters were then compared with those of burn patients admitted in the preceding decade (1977 to 1979) (1) by using a $t$-test with a test for variance.

\section{Patient population}

\section{RESULTS}

Patients ranged in age from 15 days to 18 years, with a mean age of 3.5 years. The peak incidence of scald burns was at 15 to 17 months of age. This contrasted with a more uniform distribution for flame burns. As in the past, most burn patients were male $(65 \%$ of this study population and $68 \%$ in the previous decade).

\section{Etiology}

Scald burns accounted for $69 \%$ of admissions (175 of 255) compared with 58\% (104 of 179) 10 years before. Flame burns accounted for only $14 \%$ (35 of 255) of admissions compared with $32 \%$ (57 of 179) in the previous decade. More burns were of the 'other' etiology category in the recent dec- 


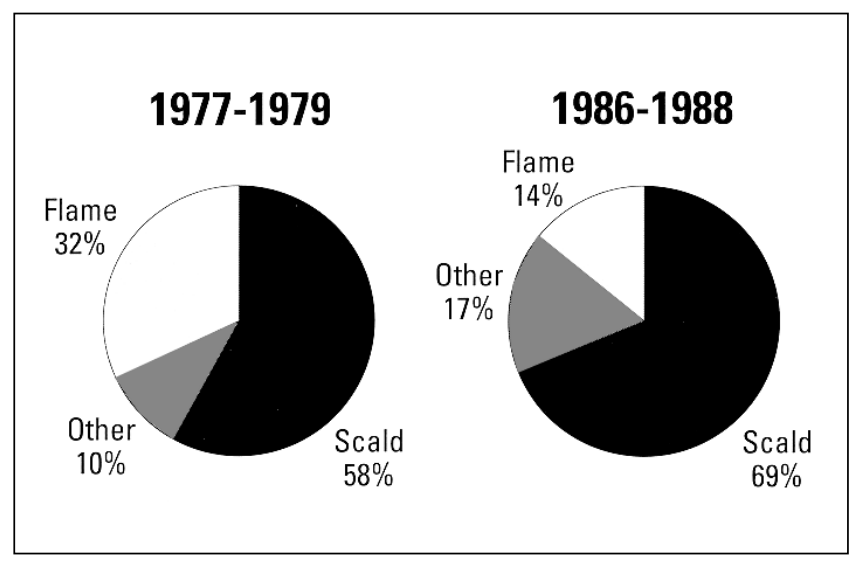

Figure 1) A comparison of the causes of pediatric burns between two decades, 1977 to 1979 and 1986 to 1988

ade. These included flash, chemical, sun and electrical burns. As a group, these patients comprised $17 \%$ of burn patients in the 1980 s cohort and only $10 \%$ in the prior decade (Figure 1). All differences were statistically significant $(\mathrm{P}<0.05)$.

Factors contributing to burns included cerebral palsy in a patient who fell into a bathtub of hot water. Two patients had myelomeningocele, one sustained a contact burn during the molding of a knee brace and another sustained a scald burn while showering. Four burns, all scalds, were the result of documented child abuse. Other suspected cases were investigated, but it was determined that they did not involve abuse.

Distribution: The face, hands, arms, legs and chest were the most frequently injured areas, as has been reported in other burn series (2,3). Scald burns were mostly partial-thickness; flame burns were more equally divided between full- or partial-thickness injuries (Table 1). The mean percentage body surface area (BSA) burned was $9.0 \%$. The distribution of patients according to the percentage BSA burned showed that $74 \%$ of the patients had burns of $10 \%$ BSA or less, $18 \%$ had burns between $11 \%$ and $20 \%$ BSA, $4 \%$ had burns between $21 \%$ to $40 \%$ BSA and $4 \%$ had burns greater than $40 \%$ BSA. Again, flame burns proved to be more serious, with a mean percentage BSA burned of $22.1 \%$ compared with $8.2 \%$ for scald burns, $3 \%$ for contact burns and less than $1 \%$ for electrical burns (which almost exclusively involved the oral commisure).

Associated injuries: Two patients sustained skull fractures with their burn injuries. One case was associated with a flame burn, and the other was the result of child abuse.

Duration of stay: Mean length of hospital stay (2.5 weeks) was unchanged from previous years. In $10 \%$ of cases ( 25 of $255)$ there was a delay of at least $24 \mathrm{~h}$ in the presentation for medical care. In another $12 \%$ (32 of 255), out-patient management had been attempted initially before it became apparent that admission would be required.
TABLE 1: Depth of burns of 255 burn patients admitted to The Hospital for Sick Children, Toronto, Ontario from 1986 to 1988

\begin{tabular}{lcccc}
\hline & Overall & Scald & Flame & Other \\
\hline Partial-thickness & 201 & 159 & 16 & 26 \\
Full-thickness & 54 & 17 & 22 & 15 \\
\hline
\end{tabular}

Management: Management of a burn begins at the time of injury. In some cases, cool water was applied to the affected area; however, many home remedies were also initially used in the management of scald and contact burns that occurred at home. Butter, petroleum jelly, olive oil, iodine, soy sauce, toothpaste and tomato paste with lemon juice were some of the substances used before the patients presented for medical care.

Eighty-nine (35\%) patients required intravenous resuscitations; the same proportion of patients that required intravenous fluid in the 1970s cohort. As in the past, a greater proportion of flame-burn victims were at risk of developing dehydration and shock compared with victims of scald burns (77\% and 34\%, respectively). Six patients required escharotomies on admission. Eighty-six (34\%) patients required skin grafting; $49 \%$ of burn patients managed in the preceding decade were skin grafted. As in the past, flame burns were more serious, with $69 \%$ of these patients requiring skin grafting. In contrast, $28 \%$ of patients with scalding required grafting.

Complications: Complications of burn injuries included upper respiratory infections and gastroenteritis, as well as hematuria from hemolysis associated with a formic acid and chemical burn. Six cases of contact dermatitis were apparently due to chlorhexidine digluconate/silver sulfadiazine (Flamazine-C, Smith and Nephew) sensitivity. Inhalational injuries were clinically and radiologically diagnosed in eight patients with flame burns. One patient who had a skull fracture associated with a burn experienced one seizure. A patient who had an ischemic foot subsequent to a flame burn required an ankle disarticulation. Two victims of flame burns suffered myocardial infarctions after their burns.

Two deaths occurred during the study period, both the result of flame burns. One patient with a 75\% BSA burn died on day 52 of burn wound sepsis with hypothermia; the other patient with a $60 \%$ BSA burn died of similar causes on day 12 . The two deaths represent a mortality rate of $0.78 \%$, compared with a mortality rate of $2.2 \%$ in the prior decade's cohort, which was also due entirely to flame burns.

\section{DISCUSSION}

Comparing the two decades studied showed an increase in the proportion of scald burns in the latter decade. At the same time, the proportion of more serious flame burns decreased. Possible reasons for these changes include increased referrals of burn cases including severe scald burns from peripheral and community hospitals, and legislation and media 
attention that has been directed towards the use of flame retardant materials in bed clothing and cribs.

Scald burns require further preventative efforts (5-7). Several risk factors need to be considered. One-fourth of adults may be unaware of the dangers of hot water $(5,8)$. Many households have hot water heaters set at dangerous temperatures that can cause full-thickness burns in adults' skin after only 2 to $5 \mathrm{~s}$ of exposure (7-10) and even more rapidly in the thin skin of young children. As many as $85 \%$ of these burns may occur in persons unable to remove themselves quickly from hot water, such as young children and the elderly (11). Many serious tap water scald burns could be prevented by lowering hot water settings to a maximum of $48.9^{\circ} \mathrm{C}$ to $54.4^{\circ} \mathrm{C}\left(120^{\circ} \mathrm{F}\right.$ to $\left.130^{\circ} \mathrm{F}\right)(5)$.

In Canada in 1986, the Federal Hazardous Products Act mandated the use of flame retardants in children's bed clothing sized 0 to $6 \mathrm{X}$ (4). This was updated by a federal regulation in 1987 to include children's sleepware up to size 12.

The future efforts of this burn unit will be directed to-

\section{REFERENCES}

1. Lewis PJ, Zuker RM. Childhood scald burns: An inquiry into severity. J Burn Care Rehabil 1982;3:95-7.

2. Munro IR, Farmer AW, Csima A. An analysis of burns in children. Can Med Assoc J 1967;97:459-63.

3. Farmer AW, Lawler WR. Review of burn admissions at The Hospital for Sick Children. Plast Reconstr Surg 1956;18:386-401.

4. Règlement sur les vêtements de nuit pour enfants. Directives sur les mesures correctives. Division des produits inflammables. Direction de la sécurité des produits. Dosier no: 10147-597. Ottawa: Consommation et Corporations Canada, 1986.

5. Katcher ML, Landry GL, Shapiro MM. Liquid crystal thermometer use in pediatric office counseling about tap water burn prevention. Pediatrics 1989;83:766-71.

6. American Academy of Pediatrics, Committee on Psychosocial Aspects wards preventive education, hot water regulation and education about acute home management of both scald and flame burns. This could be accomplished by teaching parents and students with school visit programs by members of the burn team.

\section{CONCLUSIONS}

During the three-year study period, 255 burn patients were admitted to The Hospital for Sick Children, Toronto, Ontario. Compared with the prior decade's cohort, there was a lower proportion of serious flame burns than scalds and burns of other causes. We hope that this represents a trend, perhaps due to increased media attention and legislation preventing the use of flammable materials in cribs and bed clothing. The continued use of flame retardants should have a beneficial effect as well. Flame burns were the most serious injuries, requiring more aggressive management and more frequent need for skin grafting, and leading to more complications than other types of burns.

of Child and Family Health. Guidelines for Health Supervision. Elk Grove Village: American Academy of Pediatrics, 1985.

7. Webne S, Kaplan BJ, Shaw M. Pediatric burn prevention: An evaluation of the efficacy of a strategy to reduce tap water temperature in a population at risk for scalds. J Rev Behav Pediatr 1989;10:187-91.

8. Katcher ML. Prevention of tap water scald burns. Am J Public Health 1978;77:1195-7.

9. Feldman KW, Schallwer TS, Feldman JA. Tap water scald burns in children. Paediatrics 1978;62:1-7.

10. Moritz AR, Henriques FC Jr. Studies of thermal injury II: The relative importance of time and surface temperature in the causation of cutaneous burns. Am J Pathol 1982;23:695-720.

11. Katcher ML. Scald burns from hot tap water. JAMA 1981;246:1219-22. 